\title{
Constraints in the Implementation of Public Private Partnerships in Afghanistan
}

\author{
Sebghatullah Karimi ${ }^{1}$ and Poorang A. E. Piroozfar ${ }^{2}$
}

\begin{abstract}
Traditional procurement methods have repeatedly failed to deliver projects on time and to budget in Afghanistan, and there are serious concerns about quality, cost, time and sustainability. The Afghan government has no choice but to partner with the private sector in order to meet the increasing demands on delivery of public projects. Therefore, Public Private Partnerships (PPPs) has been considered as an alternative to traditional procurement methods. The rationale is that there are no PPPs without constraints but people, even in the most insecure environments, respond to economic incentives in a rational way. This research sets out to identify the key constraints that affect the implementation of PPPs in Afghanistan. A critical review of the literature was conducted to evaluate the nature and structure of PPPs and key implementation issues, constraints influencing the implementation of PPPs and Afghanistan political, economic and social environment. 23 constraints were extracted from literature review and included into a questionnaire. The questionnaire was sent to stakeholders involved in developing infrastructure projects in Afghanistan in order to assess the degree of influence of constraints on PPPs. To establish the rating effect of constraints, the importance index was deployed. The result indicates that Afghanistan is facing with greater challenges in provision of infrastructure projects and services of which security, corruption, lack of capacity coupled with lack of funding are just to name a few. Based upon these findings, the paper recommends action on key drivers for enabling PPPs in Afghanistan.
\end{abstract}

Keywords: Afghanistan, Constraints, Developing Countries, Infrastructure Projects, Public Private Partnership,

\section{Introduction}

The importance of modern infrastructure and services in economic growth and poverty alleviation has long been recognised in both developed and developing countries. The World Bank survey indicates that a $1 \%$ growth in infrastructure stock is associated with a $1 \%$ growth in GDP. Other researches have concluded that East Asia's much higher investment in infrastructure explains a large part of its faster growth than Latin America (World Bank/PPIAF 2009).

Traditionally, the procurement method to develop infrastructure projects is dominated by public sector funding and maintenance, but in many developing countries the result has been disappointing (ADB 2008). Some governments have failed to provide critical infrastructure services to their citizens. Chronic inefficiency, poor pricing policies coupled with fiscal pressures and corruption meant that the public sector could not provide adequate services to existing consumers (ADB 2008). On the other hand, the success of private sector in delivery of infrastructure services encouraged many governments to

1 Kabul Polytechnic University, Construction Faculty, Karta-e- Mamorin , Districts \#5, Kabul, Afghanistan. E-mail: s.karimi@kpu.edu.af

2 University of Brighton, School of Environment and Technology, Cockcroft Building, Lewes Road, Brighton, East Sussex BN2 4GJ. UK. E-mail: A.E.Piroozfar@brighton.ac.uk 
involve the private sector in the provision and financing of infrastructure projects using Public Private Partnership (PPP) procurement method.

Despite being practiced for a relatively long period of time, if PPP is appropriately deployed as a way of facilitating private provision to help meet an increasing demand for public infrastructure, it still can prove an efficient alternative procurement method to other more conventional methods. PPP is characterised as a long term contractual agreement between public and private sectors, whereby rewards and risks are shared for the purpose of developing public facilities (Akintoye, et al 2003). The main aim of PPP for the public sector is to achieve value for money (VfM) in the services provided while ensuring that the private sector firms meet their contractual obligation properly and efficiently (Grimsey and Lewes 2002). It is believed that PPPs will facilitate the development of adequate infrastructure and services, and will help resolve problems related to traditional procurement such as inefficiency, unreliability and poor fiscal management, and will also address other factors such as short political tenures (government rush) and rent seeking behaviour from various interest groups. Infrastructure sector challenges will be resolved through taking advantage of private sector strengths such as (i) Management efficiency, (ii) Newer technologies, (iii) Workplace efficiencies, (iv) Cash flow management, (v) Personnel development, (vi) Shared resources and platforms and (vii) Access to diverse sources of capital (ADB 2008).

It is argued that private sector has more discipline in translating the government's strategic intent into actions and results on a permanent basis which has been an issue in public sector in most developing economies (ADB 2008). Therefore, most developed and developing nations are moving from the role of infrastructure developer and operator to facilitating and governing roles.

After three decades of war and conflict in Afghanistan, the performance of the public sector has been deteriorated due to physical damage, lack of government supervision, and scarcity of resources and expertise. Repeated pledges for administrative reforms have not materialized and the performance of the public sector has not yet improved significantly. The financial reality of the government budget indicates that economic optimization may not be reached or even achievable under traditional procurement methods because it requires thriving economy, efficiency, quality, fairness, and transparency. Therefore, there is a growing need for a procurement system to be able to overcome these challenges and improve the effectiveness, fairness and transparency in procurement of public projects in the country.

In line with the global trends, using PPP as an option for the delivery of infrastructure projects will enable the Afghan government to (i) mobilize private sector money, expertise and capacities, (ii) develop long-term relationship with private sector (iii) share risks and rewards and avoid lop-sided agreements. This method allows the private sector to use and perform lifecycle costing (LCC) in order to improve maintenance which has seriously lacked at national level, resulting in deplorable and derelict infrastructure in many parts of the country.

However, a shift from traditional procurement methods to PPP is not an easy task. PPPs involve complicated structures that require new skills and capacities; what the Afghan public sector traditionally lacks. According to UNECE (2008) one of the key challenges facing the governments is that despite the traditional procurement methods, which focus on inputs, PPPs requires skills to identify the output of the projects. In addition, the management of PPP contracts is complex, demanding, prone to failure, and subject to abuse by unscrupulous individuals, firms or politicians, unless controlled and disciplined, through highly transparent procedures, and professional contracts and conscientious monitoring processes. 
PPP is still in infancy in Afghanistan and a new procurement method to the Afghan construction industry. Little research has been done and the subject has rarely been discussed in academia. The government needs to identify risks and recognize the key constraints, if they are to use PPPs as an alternative to traditional procurement methods. Key questions such as how the parties can approach PPPs; and what technical, financial, legal and regulatory constraints must be overcome; are needed to be fully investigated and evaluated. Hence, this research aims to address these issues by identifying the key constraints that affect the implementation of PPPs in Afghanistan. The research will identify and analyze the importance of each constraint on PPPs and will provide recommendations for further studies.

\section{Research Design and Methodology}

The research is commenced with in-depth critical review of literature. The nature of Afghanistan's political and economic environment is investigated. Detailed PPP and PFI (Private Finance Initiative) case studies of projects executed in Nigeria, Cyprus, South Africa, India and Pakistan have been studied to find the closest precedents from which lessons can effectively be learned. This vast literature review and case studies provide the information and foundation for identifying the key constraints that may influence the implementation of PPP projects. Additionally, two case studies on the subject of 'Construction Productivity in Afghanistan, (Karimi and Gidado 2012) and 'Construction Delay in Afghanistan' (Niazi and Gidado 2012) were used to pave the ground for understanding the construction industry and infrastructure development in Afghanistan.

The results from literature review and relevant case studies were then used to develop a questionnaire. The questionnaire was aimed at top private sector organisations, government officials and foreign investors. Participants were carefully selected based on their reputation and expertise in the area of infrastructure development. The questionnaire was prepared in English translated into Persian, and both English and Persian versions were sent to the respondents to increase the response rate. Therefore, the practitioners were contacted and met by one of the authors during a trip to the country prior to sending out the questionnaires, both the English and Persian versions were pilot-tested with the University of Brighton and Kabul Polytechnic University academic staff as well as with three construction practitioners in Afghanistan.

Feedback from the pilot study suggested that some of the questions were misleading; some were ambiguous and needed to be rephrased or restructured. Moreover, some of the questions were not relevant to the aim or objectives of the study, and were intrusive, breaching participants' confidentiality or creating duplicity. After careful consideration of the feedback received through piloting stage, the final version was produced including the following sections:

Section A: general information about organisation and respondent. The aim of this section was to clarify on the type of organisation (public sector, private sector, financial institution) and characteristics of respondent (position and experience).

Section B: was aimed at strengths and weaknesses in the current procurement methods in Afghanistan. It helped understand the types of procurement methods that are currently used for the delivery of infrastructure projects and how the respondents would rate their experience in this regards.

Section C: correspondingly included the constraints that may influence the implementation of PPP projects in Afghanistan. Section C was intended to examine the opinion and perception of participants on the impact and importance of constraints on PPPs in Afghanistan. 


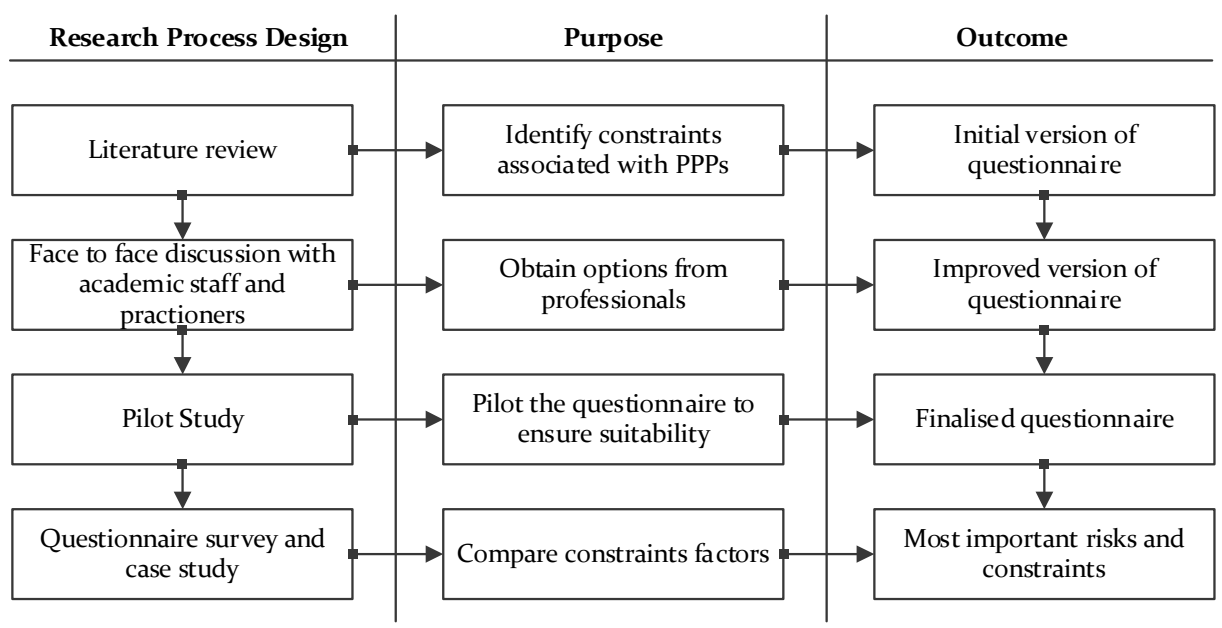

Figure 1: The processes of research design

The respondents were asked to rank importance of constraints on PPPs using a 5-point Likert scale ( $1=$ very low influence; $2=$ low influence; $3=$ average influence; $4=$ high influence; and $5=$ very high influence). This type of scale has been found to be acceptable in other construction management research. For example, Wang et al. (1999) used similar approach to investigate risk criticality in China's BOT (Build-Operate-Transfer) projects. Furthermore, respondents were asked to add comments and rate factors that they believe have an effect on the implementation of PPPs, if not already included in the questionnaire. The summary of research design process and the purpose and outcomes of each stage is shown in Figure 1.

\section{Data Collection}

The questionnaire was distributed to 35 participants. A total of 18 questionnaires were completed, representing a response rate of 51 per cent. 4 out of those 18 were not deemed useable due to sketchiness of the data provided. The remaining 14 questionnaires had positive and reliable responses. Hence, data analysis is based on 14 questionnaires. Organisations contributed to the survey are government organisations (36\%), construction companies (36\%), consultants (21\%), and one private bank (Figure 2).

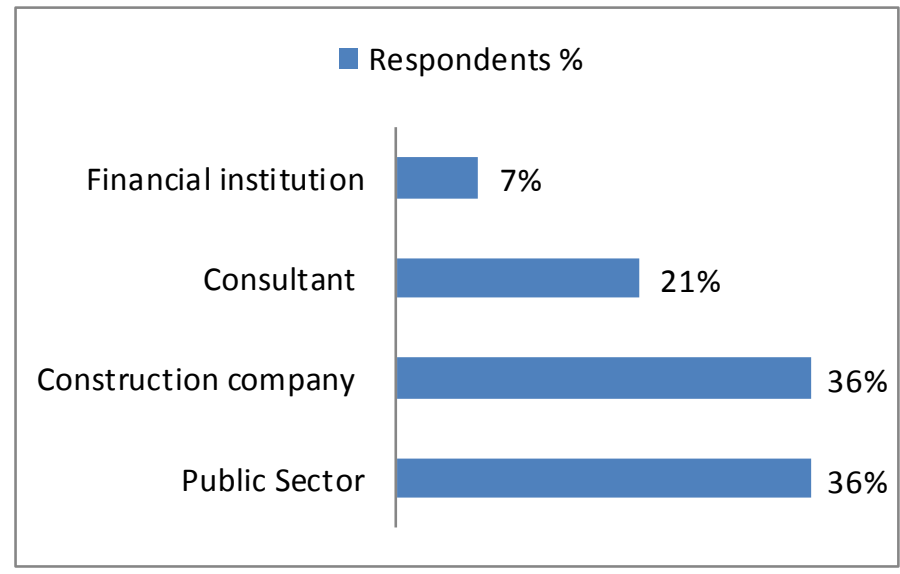

Figure 2: Type of Organisations

Despite direct contact for several times, the Ministry of Finance and Ministry of Mining did not oblige to fill the questionnaire, asked for official permission from a high authority which is very hard to obtain. However, the organisations were involved almost with all types of infrastructures and public projects, with majority involved in buildings (Schools, hospitals and housing) with a weight of $41 \%$ and road and infrastructure projects $33 \%$ (Table 1). 
Table 1: Type of Infrastructures and Projects Undertaken by Organisations

\begin{tabular}{lll}
\hline Type of Projects & Weighting & Percentage (\%) \\
\hline Buildings (Schools, hospitals and housing) & 11 & 41 \\
\hline Roads & 9 & 33 \\
\hline Power plant & 3 & 11 \\
\hline Others & 4 & 15 \\
\hline Total & $\mathbf{2 7}$ & $\mathbf{1 0 0}$ \\
\hline
\end{tabular}

Table 2 indicates respondents' work experience. As shown, almost $80 \%$ of respondents have more than 5 years of work experience representing that respondent were generally conversant with the problems of their firms in delivery of infrastructures and public projects in Afghanistan. Due to the complex nature and structure of PPP procurement method, it is very hard to find professionals and experts that fully understand the subject, particularly in Afghanistan where lack of skill is an important issue.

Table 2: Respondents’ Work Experience

\begin{tabular}{lll}
\hline Years of experience & Number & Percentage (\%) \\
\hline 2 to 5 & 3 & 21 \\
\hline 5 to 10 & 5 & 36 \\
\hline 10 to 15 & 2 & 14 \\
\hline 15 and above & 4 & 29 \\
\hline Total & $\mathbf{1 4}$ & $\mathbf{1 0 0}$ \\
\hline
\end{tabular}

To ensure reliability and validity of data, the respondents were carefully selected. The respondents were encouraged to contact the researchers if there was any ambiguity, questions or concerns.

In addition, the authors appointed a person to communicate with respondents face-to- face, if any problem arose. The result indicated that 4 project managers, 3 construction managers, 3 academics (university professors), and 4 others (2 architects and 2 procurement officers) contributed to the survey (Figure 3)

\section{Data Analysis Method}

Relative Importance Index (RII) is chosen among others due to its effectiveness and use in construction management research, frequently (Holt 2014). Researchers who have dealt with similar subjects in Nigeria (Akerele \& Gidado 2003, and Aniekwu 1995), Cyprus

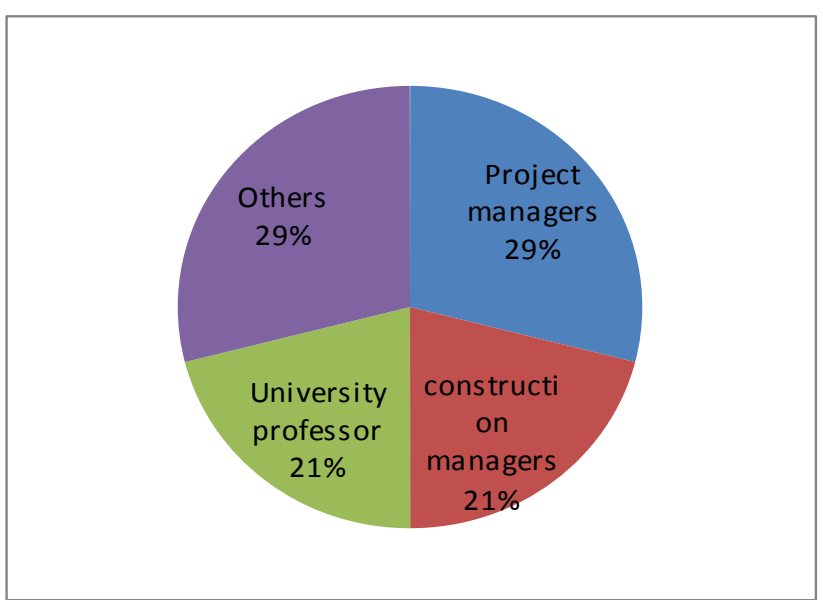

Figure 1: Respondents’ Professions (Gidado \& Smilas 2004), Malaysia (Abdul Kadir et al 2005), Gaza Strip (Enshassi, et al 2007), Iran (Zakeri, et al 1996) have successfully used RII in their studies. These methods are used for questions that use Likert Scale and require the selection of ratings (usually between 1 and 5) showing the severity of factors and/or importance of particular issues in question. In order to rank the importance of the risks and constraints included in the questionnaire, the importance index was used. This index was calculated by the following equation (Lim et al, 1995 among others): 
Importance index $=\frac{5 n 5+4 n 4+3 n 3+2 n 2+n 1}{5(n 1+n 2+n 3+n 4+n 5)} * 100$,

Where $\mathrm{n}_{1}$ is the number of respondents who answered "very low", $\mathrm{n}_{2}$ the number of respondents who answered "low", $\mathrm{n}_{3}$ the number of respondents who answered "medium" $\mathrm{n}_{4}$ the number of respondents who answered "high" and $\mathrm{n}_{5}$ the number of respondents who answered "very high"

\section{Results and Findings}

The second section of the questionnaire was aimed at identifying the strengths and weaknesses of existing procurement methods in Afghanistan. The respondents were asked to specify the types of procurement methods that they are currently using for the delivery of infrastructure projects. The analysis of the result indicates that the country infrastructure market is dominated by two type of procurement method; 'Traditional (design, bid, and build)', and 'Design and Build'. It seems that using other forms of procurement method such as 'Construction Management' and 'Prime Contracting' is less known, hence uncommon (Figure 4).

In order to identify stakeholder's satisfaction with their experience of the procurement methods they were using, the respondents were invited to rate the methods with a Likert scale of 1 (Not at all happy) to 5 (Very happy). Utilising importance index, it was revealed that respondents were more satisfied with Design and Build procurement method than the Traditional. While the importance index value for both methods is moderate,

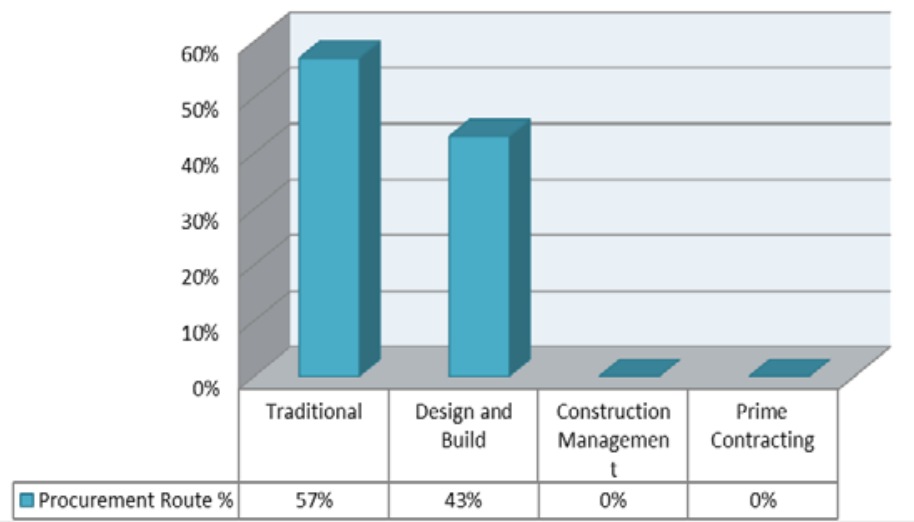

Figure 4: Existing procurement methods for the delivery of infrastructure projects in Afghanistan representing respondents were somewhat happy with the existing procurement methods in Afghanistan (table 3).

Table 3: Respondents Satisfaction with the Current Procurement Methods

\begin{tabular}{lll}
\hline Procurement Method & Importance Index & Rank \\
\hline Traditional & 55.4 & 2 \\
\hline Design and Build & 67.1 & 1 \\
\hline Construction Management & 0 & 0 \\
\hline Prime Contracting & 0 & 0
\end{tabular}

In addition, critical factors that are very important in any procurement methods were identified through literature review and case studies, and were included in the questionnaire, and then the respondents were asked to select whether included factors are met by the current procurement methods. The respondents were also requested to add and subsequently weigh any other important factors which are lacking and/or problems that they believe are facing the current procurement methods. The result indicates that all 
respondents ranked 'Quality' and 'Delivery in time' with the same weight as the most important factors which are usually disregarded in the current procurement methods. This followed by 'Life cycle management' and 'Health and safety' in positions 2 and 3 . The respondents also added 'Lack of comprehensive procurement law', 'Lack of trust and commitment between stakeholders', and 'Lack of sustainability', as major issues in existing procurement methods (Table 4). Meanwhile, as it is shown in table 4, respondents ranked lack of VfM (Value for Money) the last. Considering the importance and complexity of the concept, it seems VfM has not been defined and integrated into existing procurement methods in the country.

Table 4: Factors lacked in the current procurement methods

\begin{tabular}{lll}
\hline Factors & Weight & Rank \\
\hline Quality & 14 & 1 \\
\hline Delivery in Time & 14 & 1 \\
\hline Life Cycle Cost Management & 11 & 2 \\
\hline Health and Safety & 10 & 3 \\
\hline Cost Control & 9 & 4 \\
\hline Facilities Management (operation and maintenance) & 9 & 4 \\
\hline Stakeholder Participation & 7 & 6 \\
\hline Value for Money (VfM) & 5 & 7 \\
\hline
\end{tabular}

The third section of the questionnaire comprised the constraints that affect the implementation of PPPs in Afghanistan. The respondents were asked to rate the importance of these constraints using a Likert scale of 1 to 5 in order to establish a rating of the effect. It was found that 23 'constraints' are hindering the implementation of PPP projects in Afghanistan. 'War and insurrection/civil disturbance (Security, crime, theft, and disorder)' with an importance index of 92.9 is ranked as the most important constraint that has a high influence on the implementation of PPP projects. These findings consolidate the findings of Karimi and Gidado (2012) and, Niazai and Gidado (2012) who found 'security' and 'corruption' as the two most important factors influencing construction productivity, and substantially responsible for construction projects time and cost overrun in Afghanistan.

Tackling security and corruption becomes the greatest challenge for the Afghan government and its international partners. The World Bank group, in 2012, conducted a study on the ease of doing business in Afghanistan in comparison with other economies across the world, and ranked the country last $\left(183^{\text {th }}\right)$ in protecting investors. In addition, security which was found by the World Bank (2009) and CIPE (2010) survey seems to continue to be a major problem in the country severely impeding economic development. Insecurity complicates development of infrastructure, transportation, and other critical areas, exacerbating many other critical factors for economic growth. Insecurity can also impede the flow of human capital between nations, which is the central part of PPPs.

Respondents ranked corruption and lack of accountability and transparency as the second and third important constraints that significantly influence the implementation of PPPs in Afghanistan. This is justified, as Afghanistan was ranked 180 out of 182 countries surveyed in terms of its ability to control corruption (CPI-TI, 2011). Corruption is everywhere in Afghanistan and becomes an endemic problem. According to UNDOC, the total bribe payments were equivalent to 23\% of GDP in 2010. Corruption is not only in monetary form, but it also includes favouritism and nepotism in the disposal of aid supplies, location of infrastructure projects, and enforcement of regulation (Rodieck 2010). Based on a survey of 6500 Afghan citizens by 'Integrity Watch Afghanistan' in 2009, corruption was perceived as a normal way of doing business in the country. 
Lack of policy guidelines is ranked fourth and labelled as 'highly serious' constraint that influences the implementation of PPPs in Afghanistan. This is to confirm that undertaking PPPs without an overall PPP policy will lead to ill-defined goals and a greater likelihood of problems occurring in projects. The PPP requires coherent policies that lay down clear objectives and principles, identifying projects, and setting realistic targets and the means of achieving them, with the overall aim of winning the support of the population for the PPPs approach (UNECE 2008).

Other issue that has very serious influence on the implementation of PPPs was found to be 'lack of capacity in the public sector', ranked in position 5 of all 23 constraints. This is probably due to the fact that PPPs involve complicated structures that require new skills and capacities which are traditionally lacking in the public sector in similar economies to that of Afghanistan. It can be argued that one of the reasons of spreading corruption in Afghanistan is lack of capacity in the public sector. The government repeatedly failed to absorb international aids proactively and efficiently, and even failed to utilize its development budgets.

The success of private participation in any partnership with the government depends on the private sector having reliable access to funding. As shown in Table 5, the difficulty in securing credit from financial institutions in Afghanistan is also considered to be one of the most important constraints.

Table 5: Constraints on PPPs in Afghanistan

\begin{tabular}{|c|c|c|c|c|c|c|c|c|c|}
\hline No & Constraints & $\mathbf{n}_{5}$ & n4 & n3 & $\mathbf{n} 2$ & $\mathbf{n}_{1}$ & TR & $\begin{array}{l}\text { Imp } \\
\text { Index }\end{array}$ & Rank \\
\hline 1 & $\begin{array}{l}\text { War and insurrection/ civil disturbance } \\
\text { (Security) }\end{array}$ & 10 & 3 & 1 & 0 & 0 & 14 & 92.9 & 1 \\
\hline 2 & Corruption & 9 & 4 & 1 & 0 & 0 & 14 & 91.4 & 2 \\
\hline 3 & Lack of Transparency and Accountability & 8 & 4 & 2 & 0 & 0 & 14 & 88.6 & 3 \\
\hline 4 & Lack of policy guidelines & 8 & 2 & 3 & 0 & 0 & 13 & 87.7 & 4 \\
\hline 5 & Lack of capacity in public sector & 7 & 5 & 2 & 0 & 0 & 14 & 87.1 & 5 \\
\hline 6 & Difficulties in securing credit & 6 & 5 & 2 & 0 & 0 & 13 & 86.2 & 6 \\
\hline 7 & Lack of legal and regulatory framework & 6 & 6 & 2 & 0 & 0 & 14 & 85.7 & 7 \\
\hline 8 & Failure to apply law & 4 & 6 & 4 & 0 & 0 & 14 & 80.0 & 8 \\
\hline 9 & Lack of financial framework & 3 & 4 & 4 & 1 & 0 & 12 & 75.0 & 9 \\
\hline 10 & Poor use of feedback system & 1 & 7 & 5 & 0 & 0 & 13 & 73.8 & 10 \\
\hline 11 & Lack of capacity in private sector & 1 & 7 & 6 & 0 & 0 & 14 & 72.9 & 11 \\
\hline 12 & Terrorism and sabotage & 6 & 1 & 3 & 4 & 0 & 14 & 72.9 & 11 \\
\hline 13 & Problems of inadequate procedures (red tape) & 2 & 8 & 1 & 3 & 0 & 14 & 72.9 & 11 \\
\hline 14 & Difficulties from changing government & 1 & 8 & 2 & 2 & 0 & 13 & 72.3 & 12 \\
\hline 15 & Poor appraisal system & 0 & 6 & 6 & 0 & 0 & 12 & 70.0 & 13 \\
\hline 16 & Lack of adequate infrastructure & 0 & 7 & 6 & 1 & 0 & 14 & 68.6 & 14 \\
\hline 17 & Lack of effective value management & 0 & 5 & 7 & 1 & 0 & 13 & 66.2 & 15 \\
\hline 18 & Poor I.T. and communication system & 0 & 5 & 6 & 2 & 0 & 13 & 64.6 & 16 \\
\hline 19 & Complex negotiation & 0 & 3 & 8 & 1 & 0 & 12 & 63.3 & 17 \\
\hline 20 & $\begin{array}{l}\text { Difficulties in importing of material \& } \\
\text { equipment }\end{array}$ & 0 & 4 & 5 & 3 & 1 & 13 & 58.5 & 18 \\
\hline 21 & Access to land & 0 & 3 & 3 & 8 & 0 & 14 & 52.9 & 19 \\
\hline 22 & Cultural and social environment & 0 & 2 & 5 & 4 & 3 & 14 & 48.6 & 20 \\
\hline 23 & Difficulties in obtaining foreign exchange & 0 & 1 & 3 & 7 & 2 & 13 & 44.6 & 21 \\
\hline
\end{tabular}


This is followed by lack of legal and regulatory framework. PPPs usually involve long term contracts that require sophisticated whole life cycle costing. In the absence of adequate information on political and economic performance of the country on the years ahead, this becomes more complicated and challenging for investors to establish whole life costing. This can be reduced by offering different forms of public support in the forms of public loans, loan guarantees, equity participation, subsidies, sovereign guarantees, tax and custom benefits, escrow accounts through defining clear policy and regulatory framework. Although Afghanistan's regulatory framework is relatively well-ranked on two indicators; i.e. starting a business $\left(30^{\text {th }}\right)$ and, paying taxes $\left(63^{\text {rd }}\right)$ by World Bank (2012), it is ranked $105^{\text {th }}$ on resolving insolvency.

Respondents ranked 'Difficulties in obtaining foreign exchange' the last $\left(23^{\text {rd }}\right)$ and found it to have low influence on the implementation of PPP projects in Afghanistan. This might be due to large foreign aid flows and international military expenditures which facilitate access to foreign currencies in the country's financial market.

\section{Conclusion}

PPP has shown a sustained growth over the recent years as a prevailing procurement in many established economies across the world. Following upon the experiences from such economies, developing countries have already embarked on deployment of PPP in commissioning major public projects. The experience of developing countries is however, diverse and very deeply bound to the contextual conditions of where those projects are implemented.

Afghanistan has suffered from decades of war and political unrest coupled with many other destabilizing factors which have faced the country with major challenges in continuous investment in and successful delivery of public projects at national scale. PPP has been considered as an alternative procurement method which can engage private sector in the delivery and long term maintenance of the public projects to overcome some of public sector incapacities in this area. With this perspective, and taking into account that there has been very little, if any research carried out in this area in Afghanistan, current research was conducted to investigate the practical problems on the way of successful implementation of public projects through PPP. In doing so, using an extensive critical literature review, constraints were established as barriers to successful deployment of PPP. Subsequently drawing upon the experiences in similar economies, the country's economic, political and social environment was studied as the context of this study. At the next stage then Afghan professionals and authorities in four different sectors were contacted and asked to contribute to the study. A face-to-face meeting was arranged with all of the potential participants to explain the intent, purpose and benefits of the research. This showed that there was no common understanding of the concept and its working mechanism between those parties. This resulted in the need for a simplified briefing about the concept during those meetings before any constructive contribution can be made by the participant. Following the meetings and based on what was found in the literature, a bilingual questionnaire was designed and sent to them to complete. In addition to factors found in the literature, room was provided for adding any other prominent constraint which might have been considered specific to the Afghan context. The result indicates that Afghanistan is facing with greater challenges in provision of infrastructure projects and services. Security, corruption, lack of capacity coupled with lack of funding are among the most influential hindrances on the way of effective utilization of PPPs in Afghanistan and Afghan government needs to dedicate more time, money and resources in the areas found in this research if the safer, more promising, and more sustained growth in delivery of public projects through PPP is aimed for. 


\section{References}

Abdul Kadir, M. R., Lee, W.P., Jaafar, M.S,. Sapuan, S.M, and Ali, A.A.A (2005) Factors affecting construction labour productivity for Malaysian residential projects, journal of Structural Survey, Vol. 23 No. 1, pp. 42-54

ADB (2008) Public-Private Partnership Handbook, Asian Development Bank, Manila, Philippines

Akintoye, A., Beck, M. and Hardcastle, C. (2003), Public-Private Partnerships: Managing Risks and Opportunities, Blackwell Science, Oxford.

Aniekwu, A. (1995) The business environment of the construction industry in Nigeria. Construction Management and Economics, Vol.13, Issue 6, p. 445 - 455.

CIPE (2010) Afghan Business Attitudes on the Economy, Government, and Business Organisation s, The Centre for International Private Enterprise, available from: http://www.cipe.org

Dominowski, R.L. (1980), Research Methods, Prentice Hall, Englewood Cliff, NJ

Enshassi, A., Mohamed, S., Mustafa, Z.A., Mayer, P.E. (2007) Factors Affecting Labour Productivity inBuilding Projects in the Gaza Strip, Journal of Civil Engineering and Management, Vol 13, No 4, pp. 245-254

Gidado, K. (2000), Management of Information Flow in Design and Build Procurement System. Objects and Integration for Architecture, Engineering and Construction. Construction Research Communication Limited, Building Research Establishment, Pages 50-64

Gidado, K. and Smilas, M.,.(2004) The constraints affecting the implementation of PFI/PPP in Cyprus. Proceedings of $1^{\text {st }}$ International Conference on Commercial Management. The University of Manchester, UK, 1-4 July 2004.

Grimsey, D. and Lewis, M.K. (2002), "Evaluating the Risks of Public Private Partnerships for Infrastructure Projects”, International Journal of Project Management, 20(2),107 18.

Integrity Watch Afghanistan, (2009) "Afghan Perceptions and Experiences of Corruption: A national survey, available from: http://www.iwaweb.org

Karimi. S and Gidado. K (2012) Factors Influencing Construction Productivity in Afghanistan Proceedings ofEPPM 2012 International Conference on Engineering, Project and Production Management. University of Brighton, Brighton, UK

Niazi G. A and Gidado. K (2012) Causes of Project Delay in the Construction Industry in Afghanistan, Proceedings ofEPPM 2012 International Conference on Engineering, Project and Production Management. University of Brighton, Brighton, UK

Rodieck, M. (2010) Corruption in Afghanistan: An Aid Worker’s Experience,” New York Times At War blog.

UNECE (2008) Guidebook on Promoting Good Governance in Public-Private Partnerships, United Nations Economic Commission for Europe, UN Publications , Geneva

UNODC (2010), Corruption in Afghanistan: Bribery as Reported by Victims, United Nations Office on Drugs and Crime [Online] available from: http://www.unodc.org World Bank (2009), The Afghanistan Investment Climate in 2008, [Online] available from $<$ http://www.worldbank.org.af> (Accessed: 9/06/2012)

World Bank (2011) Afghanistan Economic Update: October 2011, Poverty Reduction, and Economic Management, South Asia Region, The World Bank

World Bank (2012) Doing Business 2012, Economy Profile: Afghanistan, The World Bank, Washington, USA

Zakeri, M., Olomolaiye, P.O., Holt, G.D, and Harris, F.C (1996), A Survey of Constraints on Iranian Construction Operative's Productivity, Construction Management and Economics, Vol 14,p. 417-426 